\title{
Experimental Study of the Performance and Emission Characteristics of a Compression Ignition (CI) Engine Using Syngas-Diesel Blend
}

\author{
Njeru Gatumu ${ }^{1,2^{*}}$ Dr. (Eng.) Hiram Ndiritu ${ }^{2}$ and Dr. Benson Gathitu ${ }^{2}$ \\ 1 . School of Engineering, Technical University of Mombasa (TUM), P.O. box 90420-80100, Mombasa, \\ Kenya
}

2. School of Mechanical, Manufacturing and Materials Engineering, Jomo Kenyatta University of Agriculture and Technology (JKUAT), P.O. box 62000-00200, Nairobi, Kenya.

*E-mail of the corresponding author: mutheesspear@gmail.com

The research is financed jointly by TUM and Self. The content contained herein is my original work.

\section{Abstract}

The main purpose of this study was to investigate the performance and emissions characteristics of the compression ignition engine when operated with several blends of syngas-diesel fuel. The aim is to identify the best conditions of fuel-blend proportion, compression, fuel ignition timing, speed and load under which the engine is to be operated for maximum power output and minimum emissions. Syngas used was generated from a bench-scale gasifier and mixed with air at mixing unit before the mixture is supplied to the engine combustion chamber for the mixing with a controlled amount of neat diesel. The gas was first cleaned and cooled before delivery to the mixing unit. Tests were done for fuel consumption, power output and emissions for each aforementioned condition. It is known, coal has been a major source of energy for many countries of the developed world, especially where coal deposits exist. This situation is expected to persist for a long time to come; more so, in light of the rapid depletion of the world's oil reserves, underdevelopment of conversion equipment for renewable energy and the uncertainty of nuclear energy. However, coal has been the major contributor to global warming and the greenhouse effect. These problems associated with coal have necessitated carrying out of studies under the clean coal technology and green coal programs. Both aimed at reducing its negative environmental impact and health hazard in power and industrial plants, and as an alternative fuel in ICE engines. This is partly achieved through the gasification of existing coal to produce a combustible gas called synthetic gas (syngas). Syngas can meet energy needs in an economical and environmentally friendly way, especially in the areas where coal is available, the price of petroleum fuels is high, or where supplies are uncertain. This study has established that a CI engine using syngas, though generates less power than an engine operated with neat diesel, emits less and fewer emission(s) and therefore is promising and even cost-competitive alternative to the conventional diesel fuel engines. Therefore, this paper has included information on the performance and emissions of $\mathrm{CI}$ engine when using syngas-diesel blend and compared it with when the engine is operated on neat diesel.

Keywords: Brake thermal efficiency (BTE), emissions, Internal Combustion Engine (ICE) specific fuel consumption (BFC), Synthesis Gas (syngas).

DOI: $10.7176 / \mathrm{JETP} / 10-1-07$

Publication date: March $31^{\text {st }} 2020$

\section{Introduction}

Diesel fuel has for a long time been one of the two most important fuel used in internal combustion engines (ICE). Where high torque and fuel economy are both required, diesel has provided the energy needed. Diesel engines have considerable advantages in the aspect of engine power, durability, fuel economy, and very low CO emissions. They are widely applied in vehicles [1]. However, they are major contributors to environmental degradation such that many developed countries have given a time-line of the years 2025 - 2050 by which time they will have phased out diesel vehicles from their cities and towns. To note is that objection to the use of diesel engines in vehicles is not due to its failure as a power plant but only because of its pollutant emissions. For that reason, there is a need to develop alternative fuel for the engine that is economical, has good performance when compared with diesel. Fuel, which produces exhaust gases with limited or no acidic gases as nitrogen oxide, NOx (NO and NO2), SOx or other objectionable pollutants such as $\mathrm{CO}, \mathrm{CO} 2$, hydrocarbons ( $\mathrm{HC}$ ) and particulate matter (soot and smoke). The main pollutants from the diesel engines are NOx (NO, nitric oxide and, nitrogen dioxide), unburned hydrocarbons (HC) and smoke. The alternative fuels under study to replace petroleum-based fuels are alcohols, 
LPG, CNG, H2, vegetable oils, biogas, syngas and LNG [2]. Gaseous fuels are the most promising to replace the fossil diesel because their combustion produces almost no oxides of Sulphur (SOx) and relatively little oxides of nitrogen (NOx) (the main constituents of acid rain) and substantially less carbon dioxide CO2 (a key contributor to the greenhouse effect) than most oil products and coal [3]

Sustaining a clean environment has become an important issue in an industrialized society. The air pollution caused by IC engines is one of the most important environmental problems to be tackled [2]. The researches available demonstrate that the syngas-diesel blend fuel can reduce air pollution and at the same time alleviate the depletion of petroleum fuels. For this to happen there is a need to study the impact of these alternative fuels on the engine performance and exhaust emissions of IC engines. The two practical sources of syngas for use in ICE are coal gasification and biomass pyrolysis. The latter process produces producer gas - a lower heating value type syngas, whilst burning of coal will produce medium to high heating value syngas, all depending on the process used and the type of coal used [4]. An overwhelming majority of researchers concentrate their effort in the study of uses of producer gases, most probably because of the economy of the biomass pyrolysis plant. The other is the positive impact, conversion of biomass has on the environment, and taking into account the major raw material for the plant is the municipal waste, which therefore helps in its management. The same is not true for coal, whose use in most cases leads to much pollution and environmental degradation. Nonetheless, where coal is available, as is the case in Kenya following the recent discovery of large deposits in Mui Basin, Kitui [5], effort must be made to exploit its readily available energy. Bates and Dolle [6] studied the application of syngas in ICE in their review work. The review stated that it is not possible to use syngas as a stand-alone fuel in compression ignition (CI) engine, because of its high auto-ignition temperature $(500 \mathrm{C})$, a temperature way beyond the maximum temperature reached by the most engine during their compression stroke. Observing that syngas should be used in dual fuel mode as a syngas-diesel blend. Diesel fuel as the pilot fuel and syngas, introduced through the engine intake air after being mixed with inlet air, as the primary fuel. Pradhan et al. [3] stated that the quality of syngas gas as a fuel is significantly poorer than gasoline and natural gas. Therefore, the engines required certain design modifications in order to be able to run on syngas gas. Sridhar et al. [7] investigated the suitability of syngas use in ICE and observed that diesel fuel saving of up to $85 \%$ was obtainable in dual-fuel engines. Further noting that syngas was more suited in diesel engines due to their higher efficiency and greater compression ratio, which usually varies between 12 and 24. Diesel engines also have better durability and, in some cases, require low maintenance than spark-ignition engines [8]. Pradhan et al. [3] also explained that because of the high compression ratio and low speeds, the de-rating of diesel engines running on syngas is only $15-30 \%$. Several studies have observed that the use of syngas in ICEs leads to poorer engine performance but improved emissions. Raman and Ram [9] reported that the CI engine in dual fuel mode has an energy efficiency generally of about $20 \%$ when using syngas compared with $45-54 \%$ for the conventional diesel engine running on neat diesel (ND). The problem becomes complicated because this efficiency is only achieved when the engine runs at full power and that efficiency falls off rapidly at partial load and low engine speeds [10].

To improve the performance and exhaust emission of a dual fuel engine the following conditions need optimisation: syngas composition, engine compression ratio (CR), engine operating load and speed fuel injection timing (IT). Azimov et al. [11] investigated the effect of $\mathrm{H} 2$ and $\mathrm{CO} 2$ compositions in syngas on the performance and emission of a four-strokes single-cylinder engine in dual fuel mode. The engine was supercharged and operated in a premixed mixture ignition in the end-gas region (PREMIER). This type of combustion was found to increase the efficiency of the engine, thus helped to enhance its performance. Moreover, an increase in the mean combustion temperature, indicated mean effective pressure (IMEP), and efficiency with an increase in hydrogen composition in syngas was noted. Hassan et al. [12] examined the effect of fuel injection timing, engine load, speed on engine performance, and exhaust emission of a four-stroke single cylinder direct injection diesel engine operated on dual fuel mode. The findings of the study were: reduced consumption of diesel fuel at all engine loads, advancing of injection timing (IT) resulted in improvement of brake thermal efficiency for all loads, lowering of CO emission for engine speeds of 2300, NOx increased with increase in load, lower exhaust gas temperature (EGT) and reduction of $\mathrm{CO} 2$ at all loads. To a large degree, Murthy et al. [1] reported the same findings in the study of the performance and emissions of dual-fuel CI engine with an exhaust gas recirculation. Hariram and Shangar [13] investigated the influence of $\mathrm{CR}$ on performance, emission and combustion characteristics of a compression ignition (CI) engine in both dual fuel and diesel modes, by varying CR with 50\% load. The result obtained showed that: EGT increased with higher compression ratios, the mechanical efficiency gradually decreased with increasing compression ratio, the brake thermal efficiency increased and brake specific fuel consumption reduced on increasing CR. Lal and Mohapatra [14] carried out an experimental investigation on a variable CR dual-fuel engine by varying compression ratios from 12-18. The observation was as the load and compression ratio increased, NOx emission increased, $\mathrm{CO}$ emission decreased as compression ratio increased. From the literature review, what is 
notable is the absence of investigation work on exhaust emissions and performance parameters of a diesel engine running on coal syngas-diesel fuels. Therefore, the effects of CR, loads and speed, IT and gas composition on the two parameters have not been comprehensively studied when used in a CI engine. Thus, there is a need for an investigation to be done in light of the large coal deposits in the country. Consequently, the present study set out to experimentally investigate the performance and exhaust emissions characteristics on a single-cylinder, variable $\mathrm{CR}, \mathrm{CI}$ engine operated on dual fuel mode with syngas as primary fuel and diesel as pilot fuel.

\section{Experimental Apparatus and Procedure}

The engine used for in this study is a $3.5 \mathrm{~kW}, 4$ strokes, single-cylinder, water-cooled, engine, with SI and CI mode facilities, variable compression ratio. The specifications of the engine are shown in Tables 1 . The engine was coupled to an eddy-current type dynamometer for loading. K-type thermocouples for tapping temperatures for incoming air and syngas, air-syngas mixture, coolant temperature, combustion chamber, inside the crankcase and exhaust gases. A bench-scale fluidized, bed-type gasifier was coupled to the engine to supply the required syngas with an air blower for supplying reactor combustion air. Flowmeters for syngas, air and exhaust gas were also fitted. The exhaust emissions were analysed in an ecom-J2KNpro gas analyser, comprising of a control module, different gas sensors and filters, a sampling probe, gas cooler, condensate evacuation unit and an integral printer. Fuel consumption was read directly from the PC monitor after obtaining the data from flow meters and transmitters in the engine information system. Piezo sensor and the crank angle sensor are connected respectively to engine cylinder and crankshaft and then to a PC processor to provide information on in-cylinder pressure for the angle turned by the crankshaft.

Table 1: Research Engine Specifications“

\begin{tabular}{|l|l|l|}
\hline S/NO & Specification & Value \\
\hline 1 & Number of cylinders & 1 \\
\hline 2 & Number of strokes & 4 \\
\hline 3 & Stroke $(\mathrm{mm})$ & 110 \\
\hline 4 & Bore $(\mathrm{mm})$ & 87.5 \\
\hline 5 & Fuel & Diesel/petrol \\
\hline 6 & Rated power $(\mathrm{kW})$ & 3.5 \\
\hline 7 & Speed (rpm) & 1500 \\
\hline 8 & Variable Compression ratio & $12-18: 1$ \\
\hline 9 & Fuel consumption (g/kWh) & 251 \\
\hline 10 & Injection pressure (bar) & 200 \\
\hline 11 & Injection timing ( bTDC) & 23 \\
\hline 12 & Cylinder capacity (cc) & 950 \\
\hline 13 & Combustion system & Direct Injection \\
\hline
\end{tabular}

The connected PC and the standard accuracies of measurement as provided by the manufacturer assisted in carrying out measurements. The tolerance of different equipment and the calculated uncertainties are shown in Table 2.

Table 2: The accuracies of the measurements and the uncertainties in the calculated results

\begin{tabular}{lr}
\hline Parameter & Accuracy \\
\hline load & $+-0.1 \% \mathrm{Nm}$ \\
Speed & $+/-0.1 \% \mathrm{rpm}$ \\
flowrates & $+/-0.1 \% \mathrm{~m}^{3}=\mathrm{s}$ \\
Time & $+/-0.25 \%$ \\
Temperature & $+/-0.25 \%$ \\
$\mathrm{NO}_{\mathrm{x}}$ & $+/-0.1 \%$ \\
$\mathrm{HCL}$ & $+/-0.1 \%$ \\
$\mathrm{CO}(\mathrm{Nm})$ & $+/-10 \mathrm{ppm}$ \\
$\mathrm{PM}$ & $+/-1 \%$ \\
$\mathrm{CO}_{2}$ & $+/-0.1 \%$ \\
\hline & Uncertainty \\
Parameters & Analysis \\
Speed & $+/-1.4 \%$ \\
BSFC & $+/-0.7 \%$ \\
BTE & $+/-1.28 \%$ \\
Load & $+/-0.9 \%$ \\
Combustion pressure & $+/-1.1 \%$ \\
\hline
\end{tabular}


The required syngas was obtained by cooling in a heat exchanger and filtering the raw gas that came from the reactor. This was necessary since syngas obtained from the available gasifier was produced at temperatures that ranged from $250-300^{\circ} \mathrm{C}$. To use this gas for ICE applications, it was cleaned of tar and dust and then cooled. A gas-to-air heat exchanger reduced the syngas temperature to almost room, which is desirable as excessively high temperature in the engine combustion chamber facilitates the formation of acidic $\mathrm{NO}_{\mathrm{x}}$ species.

To optimise the CI engine to run at maximum efficiency, the modification was done of the air supply system. A syngas-air mixing unit was fitted. The exhaust was fitted with a flow control valve to allow for the extraction of a sample of exhaust gas for testing. Figure 1 illustrates the experimental set-up. Adjustments were made to the engine $\mathrm{CR}$ and IT to determine best-operating conditions. A fitted tilting-block mechanism was used to vary the compression ratio without changing the geometry of the combustion chamber. To study the effect of varying CR on performance and emission characteristics of the dual-fuel engine, the engine performance and emissions experimental data were collected for CRs of $18,16,14$ and 12 . The standard IT of the engine is $23^{0} \mathrm{CA}$ BTDC. IT was adjusted by turning the flywheel and counting the number of teeth on the flywheel ring gear moved and noting when the injector spill. Each two teeth from a mark given by the manufacturer on the flywheel represent a crank angle of $2.2^{\circ}$. For instance, from the standard IT of $23{ }^{\circ} \mathrm{CA}$, addition of two teeth advanced injection timing to $25.175^{\circ} \mathrm{CA}$ bTDC.

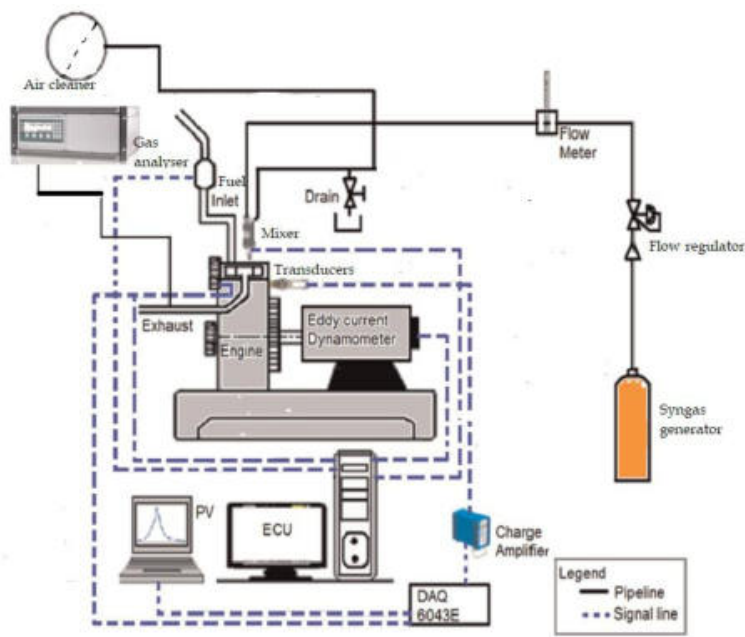

Fig. 1: The experimental setup [29]

Brake thermal efficiency (BTE) and brake specific fuel consumption (BSFC), are the parameters that are the key indicators of engine performance.

Brake thermal efficiency $\left(\eta_{B t h}\right)$ and brake specific fuel consumption (bsfc) equations 1 and 2.

$$
\begin{aligned}
& \eta_{B t h}=\frac{P_{b}}{m_{s} L H V_{S}+m_{D} L H V_{D}} \\
& \text { bsfc }=\frac{m_{S}+m_{D}}{P_{D}}
\end{aligned}
$$

where, $m_{S}$ and $m_{D}$ are masses of syngas and diesel consumed per second whose values are read from the flow meters. For this engine, and when running on neat diesel equations, 3 and 4 apply.

$$
\begin{gathered}
\eta_{B t h}=\frac{P_{d} \times 3600 \times 100}{m_{D}(\text { in } k g /(h r))+L H V_{D}} \\
\text { bsfc }(\mathrm{kg} / \mathrm{kwh})=\frac{m D(i n k g / h r)}{P_{b}}
\end{gathered}
$$

\section{Results and Discussion}

The performance and emissions of an engine when running in the two modes: dual fuel and diesel, conditions of varying load and speed, adjusted IT and CR are presented. The experimental set conditions used were: three engine speeds; 1000, 1250 and $1500 \mathrm{rpm}$, four constant loads; no-load, half, three-quarter and full loads, and four injection timings $20.8^{\circ}, 23^{\circ}, 25.175^{\circ}$ and $27.4^{\circ} \mathrm{CA}$ bTDC. The syngas substitution fractions, which were obtained by manual controls, were $100 \%, 75 \%, 50 \%, 25 \%$ and $0 \%$ (neat diesel). The engine governor controlled diesel fuel consumption. Governor regulated the fuel based on the engine speed. The diesel engine governor in dual fuel mode 
increases or decreases the amount of diesel fuel injected as necessary to maintain engine output in the face of decreasing or increasing syngas energy content [15].

\subsection{Brake specific fuel consumption (BSFC)}

Figure 2(a) shows the effect of load on BSFC for various syngas-diesel blends for a dual-fuelled CI engine at the speed of $1500 \mathrm{rpm}$ and CR 18 . The study noted that the BSFC value reduced by $90 \%$ as the load was increased from no-load to three-quarter load. Figure 2(b) shows the same effect on BSFC for the same fuel and speed but with CR adjusted to 16 . The research observed that the BSFC decreased to a third when the load was increased from no-load to full in diesel mode. Comparing the results obtained with CRs of 16 and 18: at 1500 rpm, and full load, for neat diesel, the value increased by $13 \%$ and by 3 times for $100 \%$ syngas volume flowrate (SVF), when CR was adjusted from 18 to 16 . That confirmed that the BSFC reduced with an increase of CR. This was attributed to better combustion and less heat losses at higher CR. Similar CR effects on BSFC are reported by Hariram and Shangar[13] and by Murthy et al. [1]. Dhavale et al.[16] reported similar results in the case where load and syngas volume flowrates were varied. The study observed that BSFC increased with the increased percentage of syngas substitution at part loads, while at higher loads BSFC improved with the increase of syngas substitution and attributed it to incomplete combustion of the gaseous fuel at lower loads.

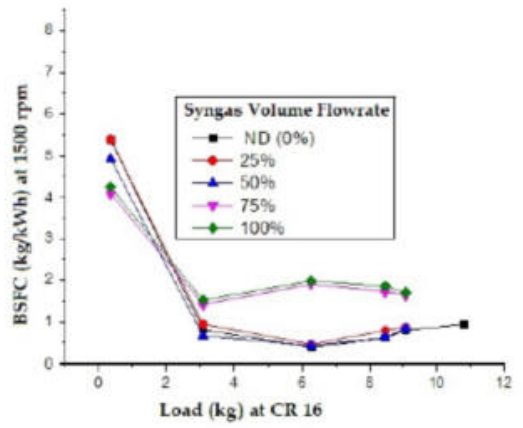

(a) Compression ratio 18

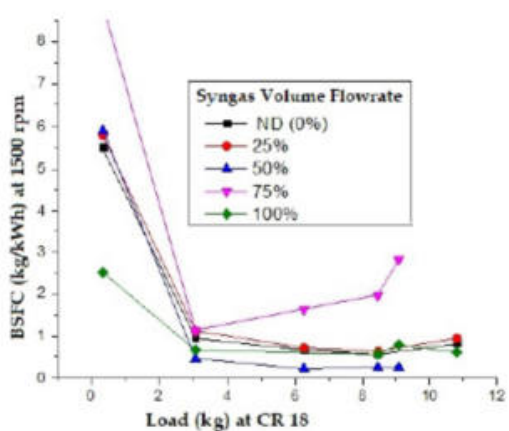

(b) Compression ratio 16

Fig. 2: Effect of varying engine load on BSFC of CI dual-fuel engine at $1500 \mathrm{rpm}$

Figures 3 show the effect of diesel substitution with syngas on BSFC of a dual fuel CI operated at $1500 \mathrm{rpm}$ for varying compression ratios and in a full load.

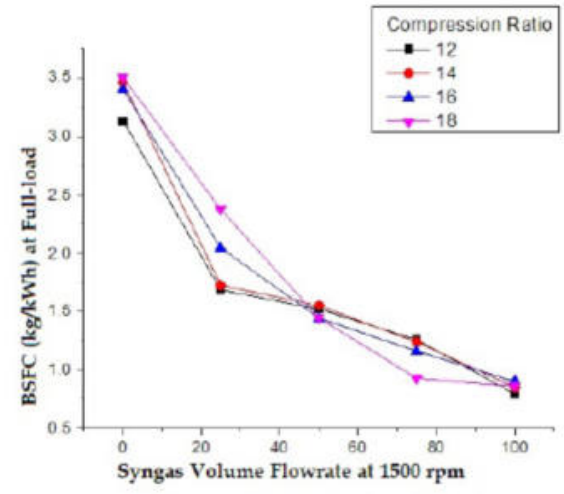

Fig. 3: Variation of BSFC with syngas volume flowrate

At full load, engine speed of $1500 \mathrm{rpm}$ and for CR 16, BSFC values increased by about two and half times for the substitution of neat diesel $(0 \%)$ with SVF of $100 \%$. The effect was attributed to incomplete combustion caused by oxygen deficiency in the combustion chamber. Ahmed et al. [17] reported similar results. Karagoz et al. [18] obtained similar results and attributed it to the low LHV of the syngas fuel, which is considerably lower than that of diesel fuel.

To improve the BSFC in dual-fuel operation, fuel injection timing was advanced to CA $25.175^{0}$ and CA $27.4^{0}$ Tests were performed for the retarded injection timing of $20.8^{0}$. Figure 4(a) shows the effect of advancing or 
retarding the fuel injection timing (IT) on the BSFC of a CI engine operating in dual fuel mode of $100 \%$ SVF. The study observed that BSFC values decreased by $7 \%$ and $13 \%$ when the engine was advanced to CA $25.175^{\circ}$ and CA $27.4^{0}$ respectively. Figure 4(b) shows the same trend under similar advance/retardation conditions but with the engine operated in diesel-fuel mode.

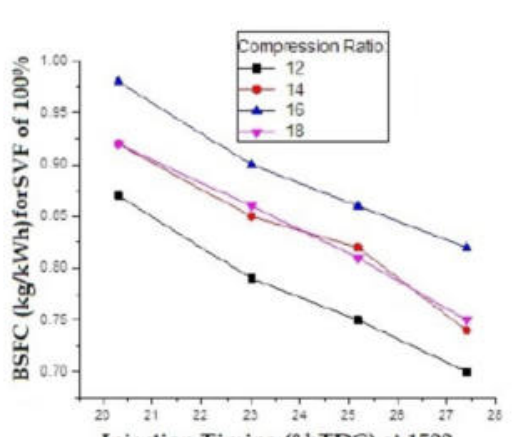

Injection Timing $\left({ }^{\circ} \mathrm{bTDC}\right)$ at 1500

(a)

Syngas volume flowrate of $100 \%$

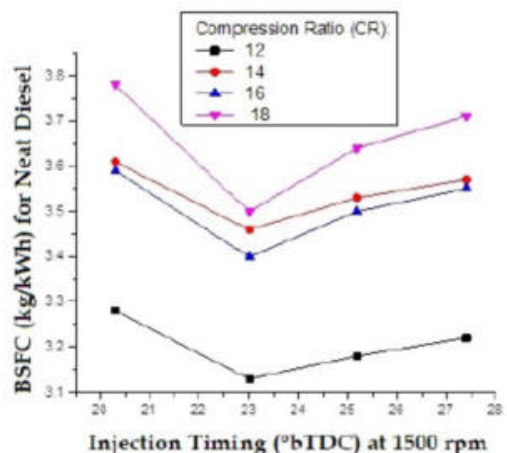

(b) Neat diesel

Fig. 4.: Variation of BSFC with injection timing and CRs

The Values of BSFC increased slightly by $4 \%$ and $6 \%$ for similar advanced conditions. Poor results that showed an increase of BSFC by $8 \%$ for SVF of $100 \%$ and $7 \%$ for neat diesel were obtained for the retarded IT conditions. The improved results in the advance mode for dual fuel mode were attributed to the increased residence time for the fuel in the combustion chamber of the engine, thus allowing it more time for combustion. Hassan et al. [12] obtained similar results with a supercharged dual-fuel engine also attributing the effect to improved combustion.

\subsection{Brake Thermal Efficiency (BTE)}

In the present study, investigations were carried out on the effects of varying load on Brake Thermal Efficiency (BTE) of a CI engine operated, first, in diesel mode and then on varying syngas volume flowrate (SVF) at set compression ratios (CRs). Figure 5 shows the variation of BTE with engine load at a speed of $1500 \mathrm{rpm}$ and CR.18.

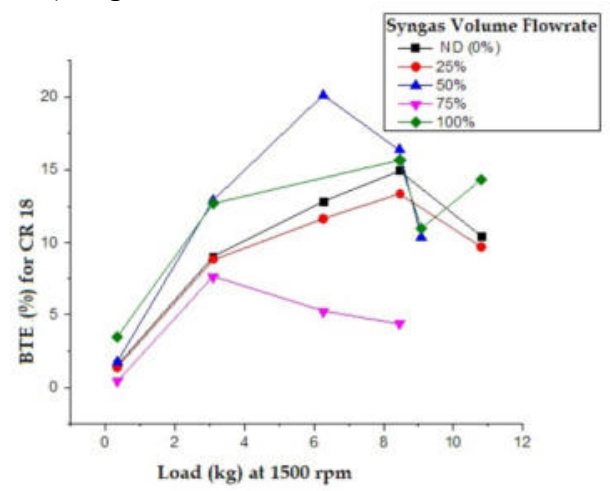

Fig. 5: Variation of load and syngas volume flowrate with BTE (CR 18).

Values of BTE obtained for diesel mode were observed to have risen through $12.2 \%$ when the load was increased from no-load to three-quarter load. BTE values for similar conditions, but with diesel substituted with $100 \%$ syngas volume flowrate (SVF) the BTE value increased by $13.4 \%$ for same increase in engine load. This demonstrated a decrease in efficiency as diesel was substituted with increased volume flowrate of syngas; by $1.87 \%$ at no-load and by $0.7 \%$ at full load. As shown in Figure 5, the maximum thermal efficiency of $21 \%$ was obtained with the CR 18 at a speed of $1500 \mathrm{rpm}$ for syngas volume flowrate of $50 \%$ at half load. This is because with a high quantity of pilot diesel the mixture of the syngas-air-diesel is richer resulting incomplete and thus higher brake thermal efficiency in dual fuel mode. Higher brake thermal efficiency is due to better mixing of syngas with air, which results in better combustion and due to wider ignition limit and high flame propagation [16,9]. The syngas engine delivers about two-third of the power at its maximum load as compared to the performance of engines using liquid fuel [19]. Mohammed et al. [20] reported that the reduction in energy density and a reduction in compression ratio result in $20 \%$ de-rating of the engine as compared to operating it on diesel. 
Figure 6 shows the effect on BTE of running the engine at lowered CR of 16 and varying load in the same fuel conditions and constant speed of $1500 \mathrm{rpm}$. It was also noted that maximum efficiencies of $22 \%$ and $21 \%$ respectively was achieved at CR 16 for half load with neat diesel and CR 12 at three-quarter loads. These results were attributed to factors like energy content of fuel mixture, volumetric efficiency and balanced air-fuel mixture, all interacting better to produce improved efficiency. A similar observation was reported by Atiqh [27] and attributed it to the same factors combining to produce the effect.

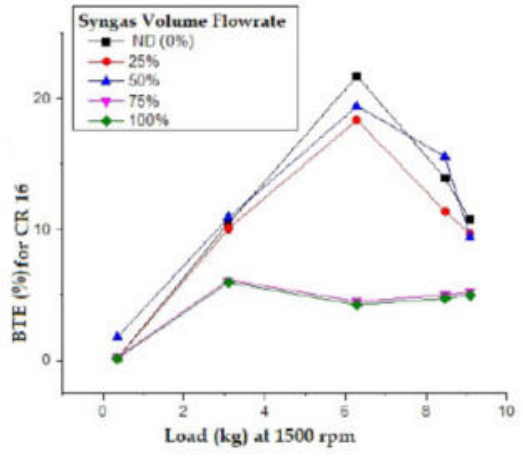

Fig. 6: Variation of BTE with load and syngas volume flowrate (CR 16)

To improve BTE of the engine in dual fuel mode, studies have identified the following methods: use of syngas with high calorific value without adding much complications and cost or optimizing adjustment of ignition timing (IT) and compression ratio(CR). The present study investigated the effect of adjusting IT and CR on BTE. Figure 7(a) shows the effect of varying CR on BTE with diesel substituted with a syngas volume flowrate (SVF) of $100 \%$ for different injection timings at a constant speed of $1500 \mathrm{rpm}$. There was a decrease of $2.6 \%$ in BTE when CR was adjusted from 14 to 18 for the IT of CA $25.175^{\circ}$. This was reversed for the advance of CA $27.4^{0}$, where a marginal increase of $0.4 \%$ was noted for the same CR adjustment. The cause for this insignificant change in engine efficiency when both CR and IT are adjusted could be attributed to the effect of varying IT adjustment interfering with the effect of varying the CR adjustment. Similar results were recorded by Kumar et al. [21] and attributed the result to better energy conversion under increased pressure and temperature.

Similarly, Figure 7(b) shows the effect of varying compression ratios on BTE at similar fuel injection timing and speed conditions, but with engine operated in diesel mode.

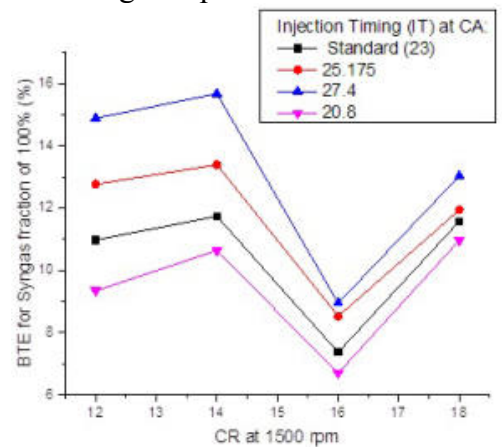

(a) Syngas volume flowrate of $100 \%$

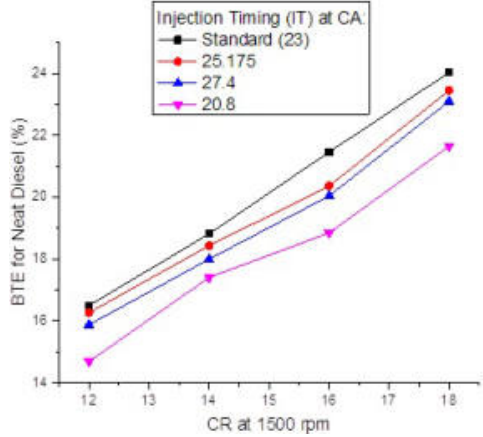

(b) Neat Diesel

Fig. 7: BTE with varying IT and CR for constant speed of $1500 \mathrm{rpm}$

The highest BTE results of $24.03 \%$ were obtained at standard injection timing (CA $23^{\circ}$ ) for neat diesel (ND) at CR 18. Adjusting CR to 16 lowered the BTE by $3 \%$. In advance of CA $25.175^{\circ}$, BTE values fell by $3 \%$ for the same CR adjustment. The fall in BTE values at lower CRs was caused by poor combustion due to low pressures and temperatures, which compromised fuel-air mixing, and combustion temperatures. Dhavale et al. [16] made a similar observation and also attributed the results to incomplete combustion. To optimise for CR at advanced IT conditions, CRs of 18 and 16 at $1500 \mathrm{rpm}$ were selected as they exhibited the highest BTEs, compared to CRs of 12 and 14. Figure 8(a) shows the effect of varying fuel IT on BTE while keeping the speed constant at $1500 \mathrm{rpm}$ and $\mathrm{CR}$ at 18, for diesel substitution with different quantities of syngas. The BTE increased by the highest value of $7.3 \%$ for syngas mass flowrate (SVF) of $50 \%$ by advancing IT to 27.40 . These results were attributed to the longer residence time for the charge in the combustion chamber (CC), which allowed for more complete 
combustion. Sayin and Canakci [22] reported the same observation and attributed it to better fuel combustion. Similarly, Figure 8(b) illustrates the effect of varying fuel IT on BTE while keeping the speed constant at 1500 rpm and CR at 16, for different levels of diesel substitution with syngas.

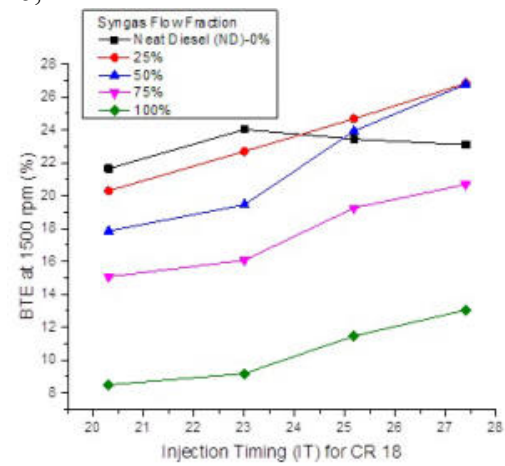

(a)

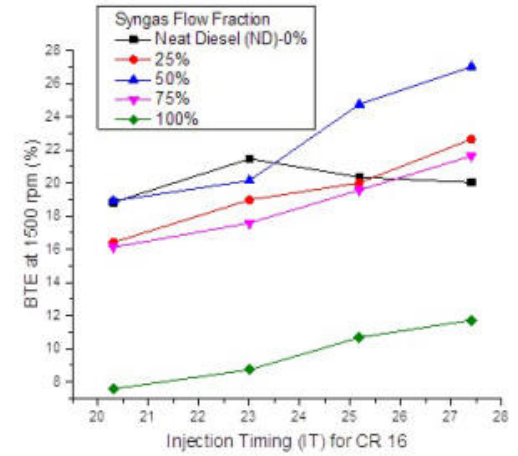

(b): Compression ratio of 16

Fig. 8: Variation of BTE with injection timing

For this CR, the BTE increased by $6.9 \%$ for SVF of $50 \%$ by advancing IT to $27.4^{0}$. An increase of about $2 \%$ was observed at IT of CA $25.175^{\circ}$ when CR was adjusted from 16 to 18 . The possible cause of the result was the longer residence time for the charge in the combustion chamber, which allowed for more complete combustion. Hariram and Shangar [13] reported that BTE was higher by almost 13\% at full load when CR was increased from 16 to 18 due to better combustion at higher compression ratios.

\subsection{Carbon monoxide (CO)}

$\mathrm{CO}$ is an intermediate product in the combustion of a hydrocarbon fuel, so its emission results from incomplete combustion [22]. Figure 9(a) shows the effects of varying compression ratio (CR) on $\mathrm{CO}$ emission under different loads for a CI fuelled with neat diesel (ND). With an increase in load from no-load to three-quarter load, CO emission decreased by $65 \%$. Similarly, Figure $9(\underline{b})$ illustrates the effect of variation of CR on CO emission under similar load conditions but with the engine operated in dual fuel mode of $100 \%$ syngas volume flowrate (SVF).

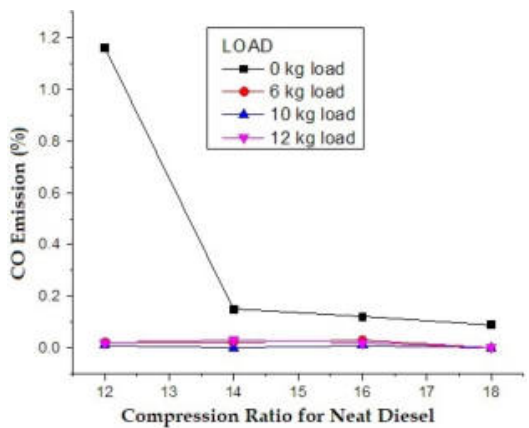

(a) Neat diesel

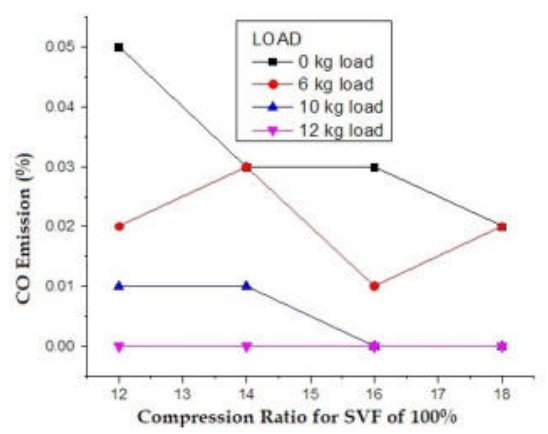

(b) Syngas volume flowrate of $100 \%$

Fig.9: $\mathrm{CO}$ emission for varying compression ratio

The study noted that at a part load of three-quarters, CO emission was eliminated for CR of 18. This could have resulted from the engine governor responding to load increase by allowing for the injection of more diesel fuel, leading to a richer air-fuel mixture with better combustion properties. Pradhan et al. [3] in reviewing works on emissions from ICEs, noted that several studies had reported $\mathrm{CO}$ emissions to have been higher for dual fuel mode at low and moderate loads but decreased with the increase of engine load attributing it to the improvement in fuel utilization.

Figure 10 shows the effect of varying compression ratio (CR) on the $\mathrm{CO}$ emission when speed is maintained at $1500 \mathrm{rpm}$ for different fuel conditions. 


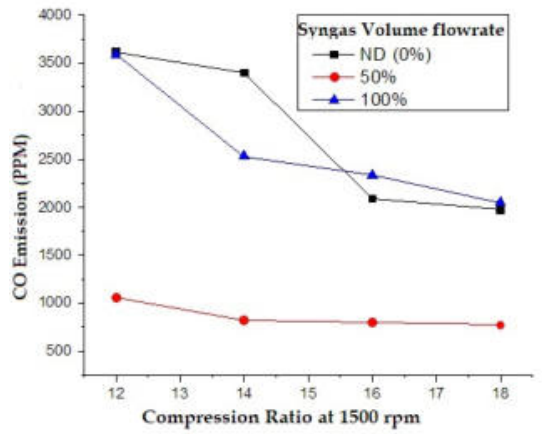

Fig. 10: $\mathrm{CO}$ emission for varying $\mathrm{CR}$ and syngas volume flowrate

$\mathrm{CO}$ emission was observed to decrease as the compression ratio increased, even at low speeds. At $1500 \mathrm{rpm}$, the $\mathrm{CO}$ emission had about $45 \%$ reduction when CR was adjusted from 12 to 18 . Similar behaviour was observed at lower speeds with $\mathrm{CO}$ emission falling by $54.5 \%$ for the same CR adjustment at $1000 \mathrm{rpm}$. Emission obtained from the engine fuelled with diesel blend of 50\% SVF was 37\% higher than from the engine when operated in diesel mode at $\mathrm{CR}$ of 18 and constant speed of $1000 \mathrm{rpm}$. The results that indicated higher CO emission in dual fuel mode were attributed to low oxygen present in the air- syngas mixture, which caused the incomplete combustion. Shrivastava et al. [23] obtained similar results and reported that the maximum concentration of CO was $10 \mathrm{ppm}$ in diesel mode and $250 \mathrm{ppm}$ in dual fuel mode. Lal and Mohapatra [14] reported the maximum concentration of CO of $700 \mathrm{ppm}$ in diesel mode and $1300 \mathrm{ppm}$ in dual fuel mode. Both studies also attributed the effect to poor combustion due to inadequate air charge in the engine cylinder.

Figure 11(a) shows CO emission results for different syngas volume flowrate (SVF) fuels and injection timing (IT) at CR 18 and speeds of $1500 \mathrm{rpm}$ and $1000 \mathrm{rpm}$. When the injection timing was advanced to CA $27.4^{0}$, the level of CO emission decreased for SVFs of $100 \%$ by $7.5 \%$ but increased for neat diesel (ND) by $5.3 \%$ at $1500 \mathrm{rpm}$. At $1000 \mathrm{rpm}$, the reduction was by $8 \%$ for the same dual-fuel mode and an increase of $50 \%$ for ND. Similarly, Figure 11(b) shows CO emission results for different syngas volume flowrate (SVF) fuels and injection timing (IT) at CR 12 and speeds of $1500 \mathrm{rpm}$ and $1000 \mathrm{rpm}$

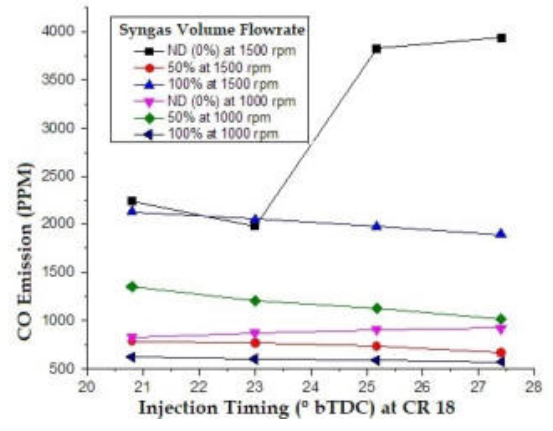

(a) Compression ratio of 18

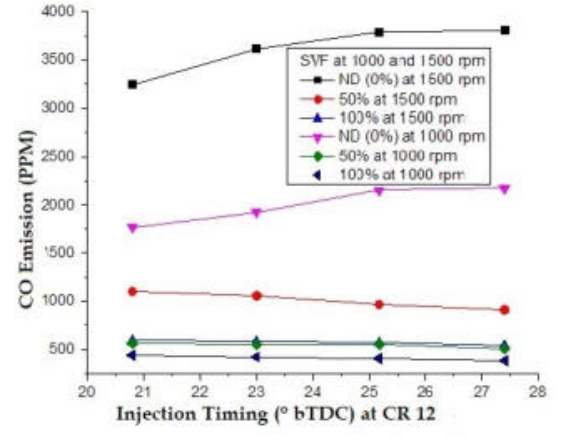

(b) Compression ratio of 12

Fig. 11: CO emissions with varying injection timing and speeds

When the engine was operated at $1000 \mathrm{rpm}$ and at $\mathrm{CR}$ of 12 for different blends of syngas and diesel; $\mathrm{CO}$ emission reduced by $8.3 \%$ for SVF of $100 \%$. Retardation of IT caused higher levels of CO emission in CR of 18 . As is gleaned from the obtained data, retarding of IT to CA $20.8^{\circ}$, increased emissions by $13.9 \%$ for ND and $4 \%$ for $100 \%$ SVF. These results are attributed to higher cylinder temperature which increased oxidation process between carbon and oxygen molecules on advancing IT. were by Nwafor [2], and Sayin and Canakci [22] obtained similar results when they tested an engine with same injection timings but different primary gaseous fuels and also attributed the effects to higher cylinder temperatures.

The main factors that promote $\mathrm{N}_{x}$ formation are high temperature, enough oxygen and sufficient reaction time 
[24]. Figure 12(a) shows the variation of $\mathrm{NO}_{x}$ emission with engine loading for each set of compression ratio (CR) in dual-fuelled engine ran on diesel mode. $\mathrm{NO}_{x}$ emission was observed to increase proportionately with the load and CR. For the diesel mode at CR $18, \mathrm{NO}_{x}$ emission increased by $8.1 \%$ for load adjustment from no-load to full. At CR 12, emission values increased by $7.9 \%$ for the same load adjustment. Similarly, Figure 12(b) illustrates the variation of the same emission under similar loading and compression conditions but with engine operated in syngas volume flowrate (SVF) of $100 \%$.

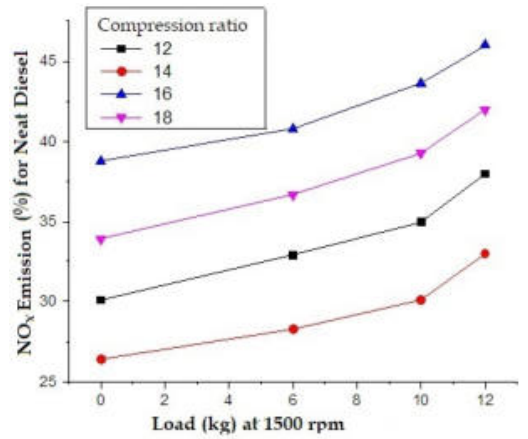

(a) Neat diesel

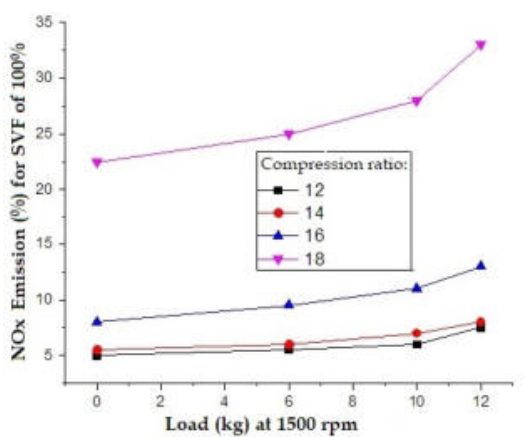

(b) Syngas volume flowrate of $100 \%$

Fig. 12: $\mathrm{NO}_{\mathrm{x}}$ emission for varying loads and compression ratios

The same effect was noted in dual-fuel mode of $100 \%$ SVF. At CR 18, emission increased by $10.5 \%$ for the adjustment from no-load to full load and $2.5 \%$ for CR of 12 for the same load increase. The results observed in the present study were attributed to more fuel injected at higher load conditions and also higher temperatures and pressure in the engine cylinder at higher compression ratios, leading to conducive conditions for $\mathrm{NO}_{x}$ species formation.

In a previous study, Dhole et al. [25] reported a maximum $\mathrm{NO}_{x}$ concentration of $904 \mathrm{ppm}$ in dual fuel mode at $80 \%$ load condition and attributed it to higher temperatures caused by the injection of more fuel at higher loads. Also Figures $12\left(\underline{\mathrm{a}}\right.$ and $\underline{\mathrm{b}}$ ) reveal that the $\mathrm{N}_{x}$ emission in diesel mode was higher by about $22 \%$ to $33 \%$ than in dual fuel mode. The lower $\mathrm{NO}_{x}$ emission obtained in dual-fuel mode is caused by the low flame propagation in the fuel-air mixture due to the presence of a high amount of syngas and a lower concentration of oxygen in the cylinder that led to lower temperatures. Shrivastava et al. [23] reported similar results and observed that maximum $\mathrm{NO}_{x}$ concentration of $325 \mathrm{ppm}$ in diesel mode and $180 \mathrm{ppm}$ in dual fuel mode at three-quarter load conditions are generated by higher temperatures and pressures obtained in the cylinder at higher load conditions.

Figure 13(a) shows the effect of varying fuel injection timing on $\mathrm{NO}_{x}$ emission from dual-fuel CI engine operated at $\mathrm{CR}$ of 18. It was observed that a higher concentration of $\mathrm{NO}_{x}$ in exhaust gases was recorded in neat diesel mode, with an increase of $30 \%$ for an advance to CA $27.4^{\circ}$. Also noted was that a decrease of $51 \%$ in emission when ND was substituted with a diesel blend containing SVF of $50 \%$. When the IT was retarded to CA $20.8^{\circ}$, a decrease of $1.3 \%$ in $\mathrm{NO}_{x}$ emission was observed on the syngas-diesel blend of syngas volume flowrate (SVM) of $50 \%$.

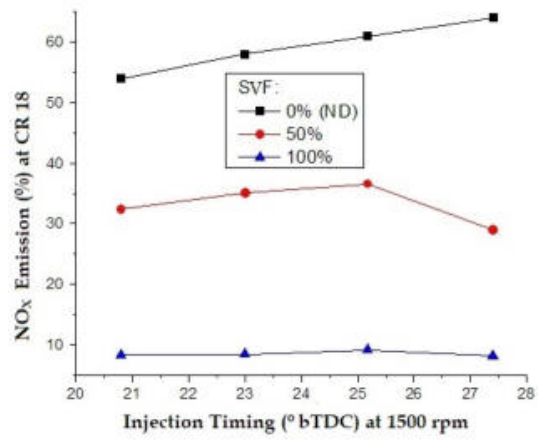

(a)

Compression ratio of 18

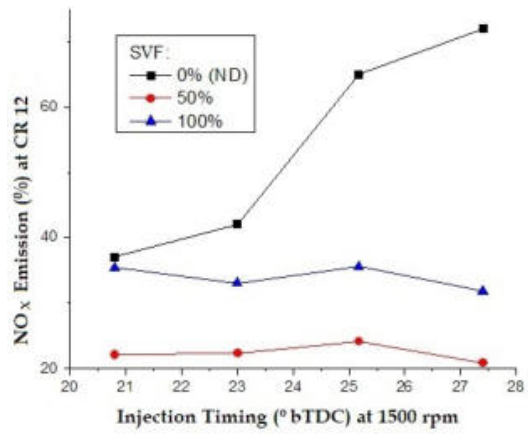

(b) Compression ratio of 12

Fig. 13: $\mathrm{NO}_{\mathrm{x}}$ emission with varying injection timing

Figure 13(b) illustrates the same emission results under the same fuel conditions but with CR set at 12 . The values obtained, indicated the emission to have decreased by $3.8 \%$ for IT advance of CA $27.4^{\circ}$ for fuel-dual mode of syngas 
volume flowrate (SVF) of $50 \%$ but increased by $6 \%$ for ND. $\mathrm{NO}_{x}$ emission decreased by $24.3 \%$ when neat diesel was substituted with a diesel-syngas blend of SVF 50\% with IT retarded. Overall, $\mathrm{NO}_{x}$ emission was observed to increase sharply with the advance of fuel injection timing. This conformed with the earlier explanation that when the fuel injection timing is advanced, the combustion time is extended as the ignition delay period is prolonged allowing for more complete combustion. hence higher temperature. Similar results were reported by Sayin and Canakci [22] and observed that when the injection timing was retarded by $6^{\circ} \mathrm{CA}$ bTDC, $\mathrm{NO}_{x}$ emissions decreased by $37.3 \%$ in part-load. Bosch [26], Hassan et al. [12] and Mahgoub et al. [28] reported similar results and also observed that retarding of the injection timing decreased the peak cylinder pressure because more of the fuel is burned after TDC.

\section{Conclusion}

This study investigated the effects of blending diesel fuel with syngas, a gaseous fuel, on the performance and emissions of a CI engine. Tests were carried out on a CI engine fuelled with diesel blended with different volume fractions of syngas. The test results for engine operation with diesel and syngas-diesel blend are analysed and compared. The conclusions deduced from the tests are as follows:

- The study showed that running the engine at its optimum operating conditions of CR of 18 and speed of $1500 \mathrm{rpm}$, it de-rated by about $32 \%$ for a dual-fuel mode of SVF $100 \%$ when compared with that of neat diesel mode. This is an indication of a poor state of fuel-energy conversion by the engine in the dual-mode. This led to the conclusion that for CI engine to run in dual fuel mode some degree of modification must be effected.

- $\mathrm{NO}_{x}$ emission decreased by $2.5 \%$ when diesel fuel was substituted with SVF of $100 \%$ for compression ratio (CR) of 18 and by about $30 \%$ for CR of 12 . Advancing injection timing reduced emissions by $3.6 \%$ in a dual-mode of SVF $100 \%$ but significantly increased by $71.4 \%$ in diesel mode, with retardation causing a decrease of $7.3 \%$ in dual mode. This led to the conclusion that advancing and retardation of injection timing, adjusting CR and controlling the quantity of syngas in the syngas-diesel blend could be used to reduce $\mathrm{NO}_{x}$ emission in $\mathrm{IC}$ engines.

- The results obtained for BTE with a fuel IT advanced to $27.4 \circ \mathrm{CA}$ were $10 \%$ higher for engine fuelled by ND than fuelled by syngas of $100 \%$ SVF-diesel blend. When CRs of 18 and 16 were analysed, the BTE values for ND were $10 \%$ higher than for $100 \%$ SVF at CR 18 and $8 \%$ higher at CR 16 at $1500 \mathrm{rpm}$. The results, therefore, show that CR adjustment has much influence on the engine power output, especially in dual fuel mode and could be used to improve engine performance in that mode.

The results reported in this study confirm that the CI engine in dual-mode is a viable alternative to traditional diesel engines albeit minor adjustment to fuel IT and CR will be required in addition to supercharging of the engine.

\section{References}

[1] K. Murthy, N. Madhwesh, and B. R. Shrinivasarao, "Influence of Injection Timing on the Performance of Dual Fuel Compression Ignition Engine with Exhaust Gas Recirculation,” International Journal of Engineering Research and Development, vol. 1, no. 11, pp. 36-42, 2012.

[2] O.M.I. Nwafor, "Effects of Advanced Injection Timing on the Performance of Natural Gas in Diesel Engine," Sadhana, vol. 25, no. 4, pp. 11-20, 2012

[3] P. Anushka, B. Prashant, and K. Anil, "Syngas as An Alternative Fuel Used in Internal Combustion Engines: A Review," Journal of Pure and Applied Science and Technology, vol. 5(2), no. October, pp. 51-66, 2015.

[4] L. L. Coq and D. Ashenafi, "Syngas Treatment Unit for Small Scale Gasification-Application to IC Engine Gas Quality Requirement,” Journal of Applied Fluid Mechanics, vol. 5, no. January 2012, pp. 95-103, 2014.

[5] M. Muthangya and D. Samoei, "Status of Water Quality in the Coal Rich Mui Basin on Kitui County, Kenya," ARPN Journal of Earth Sciences, vol. 1, no. 2, pp. 48-51, 2012.

[6] R. P. Bates and K. Dolle," "Syngas Use in Internal Combustion Engines - A Review," Advances in Research, vol. 10, no. 1, pp. 1-8, 2017.

[7] G. Sridhar, P. J. Paul, and H. S. Mukunda, "Biomass-derived producer gas as a reciprocating engine fuel An experimental analysis," Biomass and Bioenergy, vol. 21, no. 1, pp. 61-72, 2001.

[8] J. B. Heywood, Internal Combustion Engine Fundamentals, vol. 1. New York: McGraw-Hill, Inc, original ed., 1988

[9] P. Raman and N. K. Ram, "Performance analysis of an internal combustion engine operated on producer gas, in comparison with the performance of the natural gas and diesel engines," Energy Procedia, vol. 63, pp. 317$333,2013$.

[10] A. Malik, L. Singh, and I. Singh, "Utilization of biomass as engine fuel," Journal of Scientific and Industrial Research, vol. 68, no. 10, pp. 887-890, 2009. 
[11] U. Azimov, E. Tomita, N. Kawahara, and S. S. Dol, "Combustion Characteristics of Syngas and Natural Gas in Micro-pilot Ignited Dual-fuel Engine," International Journal of Mechanical, Aerospace, Industrial, Mechatronic and Manufacturing Engineering, vol. 6, no. 12, pp. 2863-2870, 2012.

[12] S. Hassan, Z. A. Zainal, and M. A. Miskam, "Effects of advanced injection timing on performance and emission of a supercharged dual-fuel diesel engine fueled by producer gas from downdraft gasifier," Journal of Scientific and Industrial Research, vol. 70, no. 3, pp. 220-224, 2011.

[13] V. Hariram and R. Vagesh Shangar, "Influence of compression ratio on combustion and performance characteristics of direct injection compression ignition engine," Alexandria Engineering Journal, vol. 54, no. 4, pp. 807-814, 2015.

[14] S. Lal and S. K. Mohapatra, "The effect of compression ratio on the performance and emission characteristics of a dual-fuel diesel engine using biomass-derived producer gas," Applied Thermal Engineering, vol. 119, no. 5 June 2017, pp. 63-72, 2017.

[15] A. Wagemakers and C. Leermakers, "Review on the Effects of Dual-Fuel Operation, Using Diesel and Gaseous Fuels, on Emissions and Performance,” SAE International Journal of Engines, vol. 2012010869, no. 201201-0869, pp. 1-18, 2012.

[16] A. A. Dhavale, A. H. Kolekar, and K. M. Jadhav, “An Experimental Investigation and Analysis for Engine Performance, Combustion and Emissions of Dual Fuel CI Engine," International Engineering Research Journal (IERJ), no. 2, pp. 1215-1224, 2015.

[17] S. A. Ahmed, S. Zhou, Y. Zhu, and Y. Feng, "Performance and emission characteristics analysis of dual-fuel compression ignition engine using natural gas and diesel," International Journal of Thermodynamics, vol. 21, no. 1, pp. 16-25, 2018.

[18] T. Sandalc1, U. O. Koylu, and A. S. Dalkılıc, "Effect of the use of natural gas - diesel fuel mixture on performance, emissions, and combustion characteristics of a compression ignition engine," Advances in Mechanical Engineering, vol. 8, no. 4, pp. 1-13, 2016.

[19] F. Y. Hagos, A. R. A. Aziz, and S. A. Sulaiman, "Trends of syngas as a fuel in internal combustion engines," Advances in Mechanical Engineering, vol. 2014, no. JANUARY 2014, pp. 0-11, 2014.

[20] S. E. Mohammed, M. B. Baharom, A. R. A. Aziz, and Firmansyah, "The effects of fuel injection timing at medium injection pressure on the engine characteristics and emissions of a CNG-DI engine fueled by a small amount of hydrogen in CNG," International Journal of Hydrogen Energy, vol. 36, no. 18, pp. 11997-12006, 2011.

[21] M. A. Ahmed, "Hydrogen Fueled Internal Combustion Engine: A Review," INTERNATIONAL JOURNAL OF INNOVATIVE TECHNOLOGY AND RESEARCH (IJITR), vol. 4, no. 4, pp. 3193-3198, 2016.

[22] C. Sayin and M. Canakci, "Effects of injection timing on the engine performance and exhaust emissions of a dual-fuel diesel engine," Energy Conversion and Management, vol. 50, no. 1, pp. 203-213, 2009.

[23] V. Shrivastava, A. K. Jha, A. K. Wamankar, and S. Murugan, "Performance and Emission Studies of a CI Engine Coupled with Gasifier Running in Dual Fuel Mode Performance and Emission Studies of a CI Engine Coupled with Gasifier Running in Dual Fuel Mode," Procedia Engineering, vol. 51, no. December 2013, pp. 600$608,2014$.

[24] Y. Liu, B. Xu, J. Jia, J. Wu, W. Shang, and Z. Ma, "Effect of Injection Timing on Performance and Emissions of DI-diesel Engine Fueled with Isopropanol,” No. Iceem, (Luoyang), pp. 133- 137, International cooperation project of Henan province, 2015.

[25] A. E. Dhole, R. B. Yarasu, D. B. Lata, and A. Priyam, "Effect on performance and emissions of a dual fuel diesel engine using hydrogen and producer gas as secondary fuels," International Journal of Hydrogen Energy, vol. 39 , no. 15 , pp. 8087-8097, 2014.

[26] R. B. GmbH, Bosch Automotive Handbook. Stuttgart, Germany: Bentley, 2008.

[27] S. M. Rahman, H. H. Masjuki, M. A. Kalam, A. Sanjid, and M. J. Abedin, "Assessment of emission and performance of compression ignition engine with varying injection timing," Renewable and Sustainable Energy Reviews, vol. 35, pp. 221-230, 2014.

[28] B. K. Mahgoub, S. A. Sulaiman, Z. A. A Karim, and F. Y. Hagos, "Experimental study on the effect of varying syngas composition on the emissions of dual fuel CI engine operating at various engine speeds," IOP Conf. Ser. Mater. Sci. Eng., vol. 100, no. 1, pp. 1-8, 2015.

[29] F. Y. Hagos, A. R. A. Aziz, and S. A. Sulaiman, "Effect of injection timing on com- bustion, performance and emissions of lean-burn syngas $\left(\mathrm{H}_{2} / \mathrm{CO}\right)$ in spar-ignition direct-injection engine," Int. J. Engine Res., vol. 17, no. 9, pp. 921-933, 2016. 